\title{
CUNEGEO
}

International Journal of Environment and Geoinformatics (IJEGEO) is an international, multidisciplinary, peer reviewed, open access journal.

\section{Anode Performance of Sustainable, Hemp-derived, Flexible, Binder-free, Carbon Fabrics in Lithium-Ion Batteries}

\section{Ozan TOPRAKCI, H. Aylin KARAHAN TOPRAKCI}

\author{
Chief in Editor \\ Prof. Dr. Cem Gazioğlu \\ Co-Editors \\ Prof. Dr. Dursun Zafer Şeker, Prof. Dr. Şinasi Kaya, \\ Prof. Dr. Ayşegül Tanık and Assist. Prof. Dr. Volkan Demir
}

Editorial Committee (March 2021)

\begin{abstract}
Assoc. Prof. Dr. Abdullah Aksu (TR), Assit. Prof. Dr. Uğur Algancı (TR), Prof. Dr. Bedri Alpar (TR), Assoc. Prof. Dr. Aslı Aslan (US), Prof. Dr. Levent Bat (TR), Prof. Dr. Paul Bates (UK), İrşad Bayırhan (TR), Prof. Dr. Bülent Bayram (TR), Prof. Dr. Luis M. Botana (ES), Prof. Dr. Nuray Çağlar (TR), Prof. Dr. Sukanta Dash (IN), Dr. Soofia T. Elias (UK), Prof. Dr. A. Evren Erginal (TR), Assoc. Prof. Dr. Cüneyt Erenoğlu (TR), Dr. Dieter Fritsch (DE), Prof. Dr. Çiğdem Göksel (TR), Prof.Dr. Lena Halounova (CZ), Prof. Dr. Manik Kalubarme (IN), Dr. Hakan Kaya (TR), Assist. Prof. Dr. Serkan Kükrer (TR), Assoc. Prof. Dr. Maged Marghany (MY), Prof. Dr. Michael Meadows (ZA), Prof. Dr. Nebiye Musaoğlu (TR), Prof. Dr. Masafumi Nakagawa (JP), Prof. Dr. Hasan Özdemir (TR), Prof. Dr. Chryssy Potsiou (GR), Prof. Dr. Erol Sarı (TR), Prof. Dr. Maria Paradiso (IT), Prof. Dr. Petros Patias (GR), Prof. Dr. Elif Sertel (TR), Prof. Dr. Nüket Sivri (TR), Prof. Dr. Füsun Balık Şanlı (TR), Prof. Dr. Uğur Şanlı (TR), Duygu Ülker (TR), Prof. Dr. Seyfettin Taş (TR), Assoc. Prof. Dr. Ömer Suat Taşkın (TR), Assist. Prof. Dr. Tuba Ünsal (TR), Dr. Manousos Valyrakis (UK), Dr. İnese Varna (LV), Dr. Petra Visser (NL), Prof. Dr. Selma Ünlü (TR), Assoc. Prof. Dr. Oral Yağcı (TR), Prof. Dr. Murat Yakar (TR), Assoc. Prof. Dr. İ. Noyan Yılmaz (AU); Assit. Prof. Dr. Sibel Zeki (TR)
\end{abstract}

Abstracting and Indexing: TR DIZIN, DOAJ, Index Copernicus, OAJI, Scientific Indexing Services, International Scientific Indexing, Journal Factor, Google Scholar, Ulrich's Periodicals Directory, WorldCat, DRJI, ResearchBib, SOBIAD 


\title{
Reaserch Article
}

\section{Anode Performance of Sustainable, Hemp-derived, Flexible, Binder-free, Carbon Fabrics in Lithium-Ion Batteries}

\section{Ozan Toprakci* iD , H. Aylin Karahan Toprakci}

Department of Polymer Materials Engineering, Faculty of Engineering, Yalova University, Yalova, Turkey

* Corresponding author: O. Toprakci

E-mail: ozan.toprakci@yalova.edu.tr

Received 18 Sept. 2020 Accepted 16 Nov. 2020

How to cite: Toprakci, O.and Karahan Toprakci, H.A. (2020). Anode Performance of Sustainable, Hemp-derived, Flexible, Binder-free, Carbon Fabrics in Lithium-Ion Batteries. International Journal of Environment and Geoinformatics (IJEGEO), 8(1): 028-032. doi.10.30897/ijegeo.796743

\begin{abstract}
Fabrication of sustainable products are of significance from many aspects recently. Industrial hemp as one of the most sustainable, environment friendly plant can be used for many applications. In this study, various sustainable, hemp-derived, binder free, flexible anode materials were prepared by the two-step carbonization method. Plain woven hemp fabric was used as a starting material. Fabrication of hemp-derived anode materials were carried out in two steps known as stabilization and carbonization. While the stabilization step was performed at $220{ }^{\circ} \mathrm{C}$ for all samples, carbonization was carried out at $600,700,800$ and $900{ }^{\circ} \mathrm{C}$ in order to optimize the carbonization process. Morphological, electrical and electrochemical characterization of the hemp-based carbon fabric anodes were carried out. Electrical resistance of the hemp-based carbon fabric anodes showed differences depending on the carbonization temperature. Electrochemical results showed that $800{ }^{\circ} \mathrm{C}$ is the optimum condition in terms of carbon yield and cell performance if the reversible capacity, cycling stability and rate capability values are considered.
\end{abstract}

Keywords: Hemp fabric, Anode, Li-ion battery, Energy storage Introduction

The importance of sustainable engineering applications has increased recently because of serious environmental regulations. Renewable, sustainable, cheap and environmentally friendly raw materials have been preferred in industry. Hemp, as one of the most sustainable plants, attracts great deal of attention for many reasons. Firstly, hemp agriculture is easy and almost no pesticide is required. Secondly, production yield is high, and it can be harvested more than once every year in the proper climate conditions. Thirdly, it has relatively low carbon footprint when compared with other natural polymers. Because of above mentioned advantages, hemp can be used in many industries. Cellulose, hemicellulose, lignin and pectin are the main components of the hemp plant. Since cellulose is mostly found in the fiber form, for many years hemp has been used in the textile and paper industry (Brosius, 2006; Horne, 2020). In addition to these, hemp has been used as a carbon source recently for many systems. In these studies various forms of hemp was used including hemp dust (Rosas, Bedia, Rodríguez-Mirasol, Cordero, research, 2008), hemp hurd (Liu et al., 2017), hemp stem (Yang et al., 2014), hemp canes (Rosas et al., 2008) and hemp fibers (Hossain et al., 2018; Mijailović et al., 2017). The hemp-derived carbon materials obtained from these studies generally showed morphologies such as activated carbon (Liu et al., 2017), activated carbon monoliths (Rosas et al., 2008) and activated carbon fibers (Mijailović et al., 2017), interconnected carbon nanosheets (Wang et al., 2013) As known, activated carbon is generally used to increase the adsorption performance of any system including gas (Liu et al., 2017), water vapor (Rosas et al., 2008), metal (Yang et al., 2014), pesticide (Vukcevic et al., 2012) etc. In addition to such applications hemp-derived carbon was investigated for its energy storage properties (Guan et al., 2019; Mijailović et al., 2017; Shi et al., 2019; Sun et al., 2016; Tan et al., 2020; Wang et al., 2013; Xiong et al., 2015; Yang et al., 2017).

In one of these studies carbon fibers were obtained from hemp fibers and activators were used in order to obtain activated carbon fibers. Process conditions esp. carbonization temperature was found significant in terms of specific capacitance (Mijailović et al., 2017). In another study various parts from the hemp plant were used in order to understand the effect of precursor morphology. Hem hurd and hemp bast were used in order to obtain 2-D activated carbon structures. Hemp hurd was determined as a better precursor. Porosity and surface area were reported to be directly related with the performance of the capacitors (Sun et al., 2016). Wang et al., synthesized hemp-derived interconnected carbon nanosheets and investigated the capacitor performance. As reported in the study that hemp-derived unique morphology was found efficient as a supercapacitor material (Wang et al., 2013).

As known for the energy storage not only capacitors but also batteries can be used. When recent technology, costs and requirements are taken into account secondary batteries are of vital importance for the energy storage. Although there are many studies carried out in the area of hemp-derived capacitors as given above; the number 
of studies for hemp-derived Li-ion batteries are limited (Guan et al., 2019; Um et al., 2018). As far as known, there are two studies in the literature. The first study for the development of hemp-based anodes for lithium-ion batteries (LIBs) was carried out by Um et al. in 2018 (Um et al., 2018). In the study hemp stem was grounded into small particles $(<1.5 \mathrm{~mm})$. Hemp was carbonized at $800{ }^{\circ} \mathrm{C}$ for $2 \mathrm{~h}$ under $\mathrm{N}_{2}$. For the activation process stem was used under $\mathrm{N}_{2}$ flow at $800{ }^{\circ} \mathrm{C}$ for $2 \mathrm{~h}$. Then one part of the material was ball-milled and other part kept as fabricated (natural hemp). Anode performance of both samples in LIBs were investigated under $300 \mathrm{~mA} \mathrm{~g}^{-1}$ current density and samples were reported to show lower capacity values until 20 cycles and stable capacity between 20-100 cycles. Ball-milled sample showed higher capacity values throughout the 100 cycles. Charge capacity values were determined as 190 and $300 \mathrm{mAh} \mathrm{g}^{-1}$ for natural hemp and activated hemp, respectively. Second study was carried out by Guan et al. in 2019. In this study, pulverized hemp stems were thermally treated at $300{ }^{\circ} \mathrm{C}$ for $3 \mathrm{~h}$ under argon atmosphere. Following that, this precursor was mixed with $\mathrm{ZnCl}_{2}$ and processed at $500-800{ }^{\circ} \mathrm{C}$ for $3 \mathrm{~h}$. Samples were grounded and treated with $\mathrm{HCl}$ and washed with water and activated carbon was obtained. In order to compare the performance of hemp-derived activated carbon, hempderived carbon was synthesized. Amorphous activated carbon materials were synthesized with sheet-like morphology and showed a high reversible capacity of $495 \mathrm{mAh} \mathrm{g}^{-1}$ after 100 cycles (Guan et al., 2019).

As obvious from the literature hemp fabric was not used as an anode source for the LIBs. Until the fabric form is obtained, many different processes are applied to the hemp plant. Although there are many steps, the most important steps are peeling off and/or mechanical separation of the fibers, spinning of the fibers and weaving. In all these steps fibers are separated from some other components (hurd etc.) and they are aligned. When fabric and other forms of hemp (hurd, stem, outer layer fibers, fiber ribbons etc.) are compared some significant differences become prominent. Firstly, fiber ratio is higher, secondly fibers and yarns are aligned. In addition to these, after the carbonization, flexible and binder free anode can be obtained. No extra step is required for the preparation of negative electrode. The most important novelty of the study stems from the fact that it is suitable for industrial production. Since fabric can be produced as desired, anode morphology and performance can be controlled. On the other hand, for other forms of hemp such as hurds, ribbons and stem repeatability of the system in terms of morphology (particle geometry, particle size distribution, porosity etc.) is difficult that is probably due to structural variations and contaminations.

In this study, hemp fabric was used for the preparation of flexible, binder-free anode materials for LIBs for the first time in the literature. Fabric samples were carbonized at different temperatures in order to obtain the best anode material. Following that flexible, binderfree hemp-derived fabric anodes were used to fabricate cells. Morphological, structural, electrical and electrochemical performance of the hemp-derived anodes were investigated.

\section{Materials and Methods}

Plain fabric made out of hemp yarn was kindly supplied from CC Textiles (Istanbul, Turkey). Hemp fabrics were purified order to remove surface finish. For the purification, hemp fabric was cut into small pieces (25 $\mathrm{mm} \times 50 \mathrm{~mm}$ ) and they were soaked into acetone at 40 ${ }^{\circ} \mathrm{C}$ for $24 \mathrm{hr}$. After washing with distilled water, they were soaked into distilled water at $80{ }^{\circ} \mathrm{C}$ for $24 \mathrm{hr}$. Then, samples were washed with distilled water 3 times and vacuum dried at $80{ }^{\circ} \mathrm{C}$ for $24 \mathrm{hr}$. At the end of this process, weight loss was $\approx 2.67 \%$.

\section{Thermogravimetric Analysis (TGA)}

Before the synthesis of the anode material, thermal gravimetric analysis (TGA) of the hemp fabric performed for the analysis of the thermal behavior. TGA was carried out by Seiko, TG/DTA 6300 between 25 and $950{ }^{\circ} \mathrm{C}$ at a rate of $10{ }^{\circ} \mathrm{C} \mathrm{min}{ }^{-1}$ under nitrogen atmosphere with a gas flow of $200 \mathrm{ml} \mathrm{min}{ }^{-1}$. TGA and derivative thermogravimetric (DTG) curves can be seen from Fig. 1. Thermal degradation of hemp fabric started $250{ }^{\circ} \mathrm{C}$ and ends around $380-400{ }^{\circ} \mathrm{C}$.

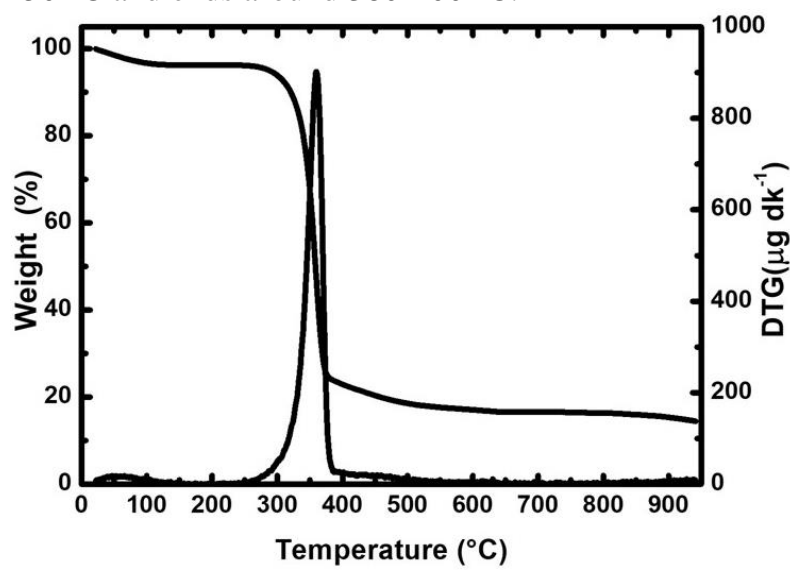

Figure 1. TGA and DTG curves of the hemp fabric

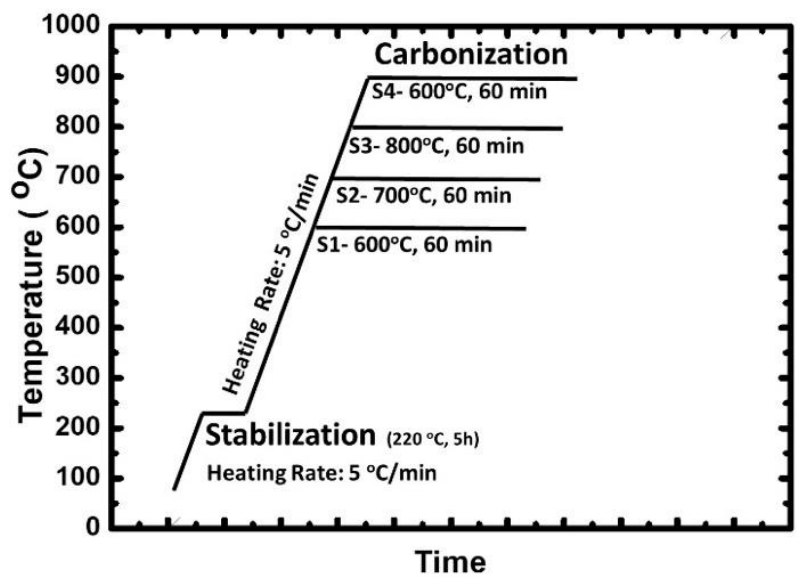

Figure 2. Thermal treatment conditions of hemp fabric

By considering the TGA data, hemp fabric samples were heat-treated in 2 steps in order to get conductive negative electrode for LIBs as shown in Fig. 2. The process was carried out by using a tube furnace (OTF-1200X, MTI). In the first step, samples were stabilized at $230^{\circ} \mathrm{C}$ for 5 
$\mathrm{h}$ under air atmosphere. After this process weight loss was around $5 \%$. Then, samples were carbonized at four different temperatures $\left(600,700,800\right.$ and $\left.900{ }^{\circ} \mathrm{C}\right)$ for $1 \mathrm{~h}$ under $\mathrm{N}_{2}$. Heating and cooling rates were kept constant $\left(5^{\circ} \mathrm{C} \mathrm{min}^{-1}\right)$ during heat-treatment.

Sample codes, carbonization temperature and carbon yield of the hemp-derived anodes can be seen from Table 1. During carbonization, hemp fibers turned into electrically conducting carbon fibers. At the end of this process 4 different hemp-derived carbon anodes were obtained.

\section{Morphology}

The morphology of the hemp fabric and hemp-derived carbon fabrics was analyzed by an optical microscope instrument (BX51M, Olympus) at 5, 10 and $20 \mathrm{x}$.

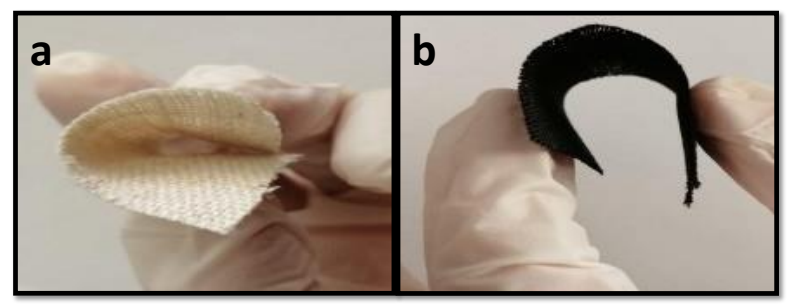

Figure 3. a) Hemp fabric and b) carbonized hemp fabric

Table 1. Sample codes and corresponding carbonization conditions, carbon yield, 4-probe resistance and thickness values of the samples

\begin{tabular}{ccccc}
\hline $\begin{array}{c}\text { Sample } \\
\text { Code }\end{array}$ & $\begin{array}{c}\text { Carbonization } \\
\text { Temperature } \\
\left({ }^{\circ} \mathbf{C}\right)\end{array}$ & $\begin{array}{c}\text { Carbon } \\
\text { Yield } \\
(\boldsymbol{\%})\end{array}$ & $\begin{array}{c}\text { Resistance } \\
(\mathbf{\Omega})\end{array}$ & $\begin{array}{c}\text { Thickness } \\
(\mathbf{m m})\end{array}$ \\
\hline H-600 & 600 & 16.25 & $8.14 * 10^{4}$ & 0.45 \\
H-700 & 700 & 15.62 & $6.72 * 10^{2}$ & 0.45 \\
H-800 & 800 & 14.96 & $1.67 * 10^{1}$ & 0.48 \\
H-900 & 900 & 14.85 & $6.33 * 10^{0}$ & 0.48 \\
\hline
\end{tabular}

\section{Resistance}

The resistance of the samples was measured by a system consists of 4-probes that were connected to a current source (Keithley 6221) and a nanovoltmeter (Keithley 2182A) under an input current of $1 \mu \mathrm{A} .4$ measurements were taken, and average values were calculated. Before the resistance measurements thickness of the samples were determined by a digital multimeter

\section{Electrochemical Characterization}

Electrochemical characterization was performed using CR2032-type cells. Half-cells were prepared in atmosphere-controlled glove-box. Half-cell consisted of an anode (binder-free and free-standing carbon fabric on copper-foil), a lithium metal reference electrode, electrolyte and a Celgard 2400 separator. The electrolyte was $1 \mathrm{M} \mathrm{LiPF} 6$ in EC:DMC:DEC (1:1:1 in volume ratio). Cyclic tests were galvanostatically performed between $0.01-2 \mathrm{~V}$ at $50 \mathrm{~mA} \mathrm{~g}^{-1}$.

\section{Results}

In order to examine the morphology, samples were analyzed by an optical microscope. Fabric morphology was analyzed at different magnifications $(5,10,20 \mathrm{x})$. While low magnification is useful in terms of observation of wider area and observing the fabric morphology, higher magnifications are useful for observing the fiber morphology. As shown in Fig. 4, untreated hemp fabric is a plain fabric and consisted of weft and wrap yarns. As obvious from Fig. 4, anode samples were carbonized without losing the plain fabric morphology regardless of the process conditions. However, weft and warp yarns shifted from the fabric axis $(\mathrm{x}, \mathrm{y})$. This is probably caused by the soft and flexible nature of the carbon fabric (Fig. 3 b).

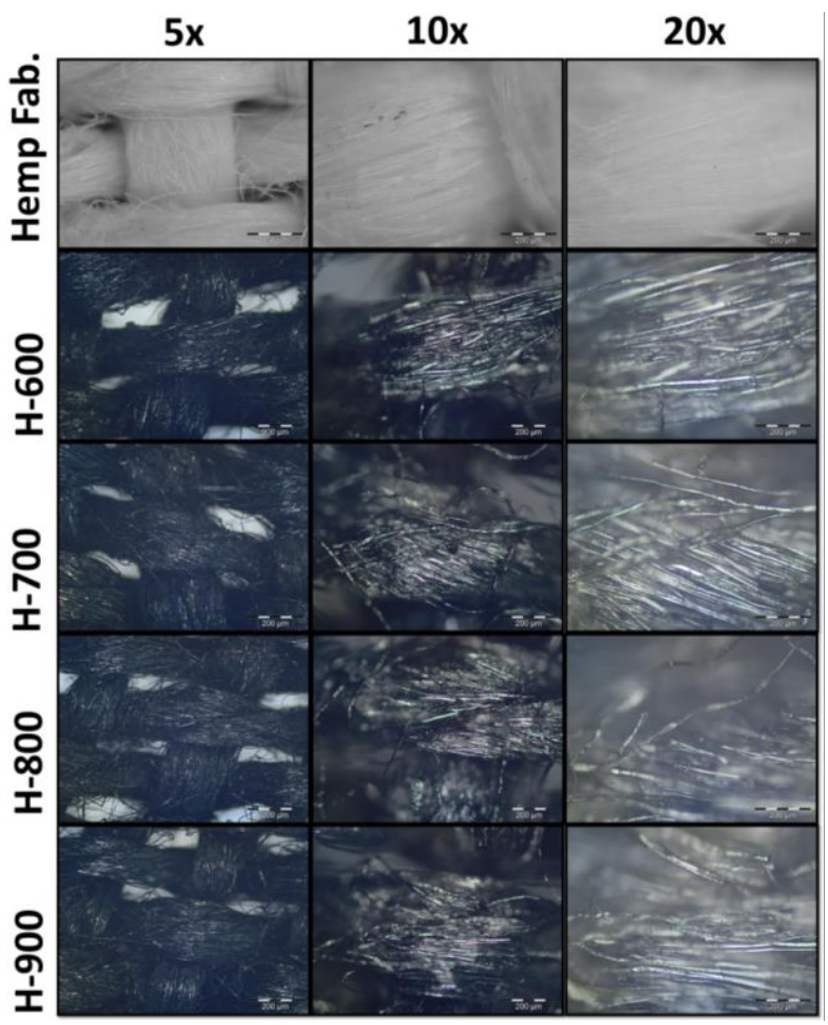

Figure 4. Hemp fabric and carbonized hemp fabrics at 5, 10 and 20x magnifications

In addition to that weft and wrap yarns showed some level of shrinkage. As can be seen, the fabric porosity increased with the increment in carbonization temperature. This is parallel with the carbon yield of the samples. As seen from Table 1, carbon yield values were $16.25,15.62,14.96$ and $14.85 \%$ for H-600, H-700, H800 and $\mathrm{H}-900$, respectively. That means around $85 \%$ of the raw material was lost. As reported in the literature this value is between 10-30 \% for cellulose based carbon fibers and This is probably caused by depolymerisation of the macromolecular chains and removal of carbon in the form of $\mathrm{CO}, \mathrm{CO}_{2}$ and tar etc. (Dumanli Windle, 2012; Huang, 2009) Although samples showed different carbonization yields, this was not observed in optical microscope images.

4-probe electrical resistance values of samples can be seen from Table-1 and Fig. 5. As obvious from these results, carbonization temperature directly affected the electrical resistance values (ERV) of the samples. While H-600 had ERV of $8.14 * 10^{4} \Omega, \mathrm{H}-700$ showed ERV around $6.72 * 10^{2} \Omega$. Two orders of magnitude drop were observed for $100{ }^{\circ} \mathrm{C}$ increase in carbonization temperature. Similar decrease was observed for $\mathrm{H}-800$ 
and $\mathrm{H}-900$ those showed ERV of $1.67 * 10^{1}$ and $6.33 * 10^{0}$ $\Omega$, respectively. Especially $\mathrm{H}-800$ and $\mathrm{H}-900$ can be used as a conductive filler for many applications. As known, cellulose based fibers do not melt during thermal treatments and good source of carbon fibers. However, these non-melting polymers lead to formation of nongraphitizable carbon fibers (Dumanlı Windle, 2012; Ishida et al., 2004; Watt Sciences, 1970). As mentioned before by increasing the carbonization temperature carbon yield decreased. That probably led to higher level of collapsing between fibers and decrease in the fiber fiber distance. All these facilitated the current flow and ER values decreased (Kwon et al., 2013).

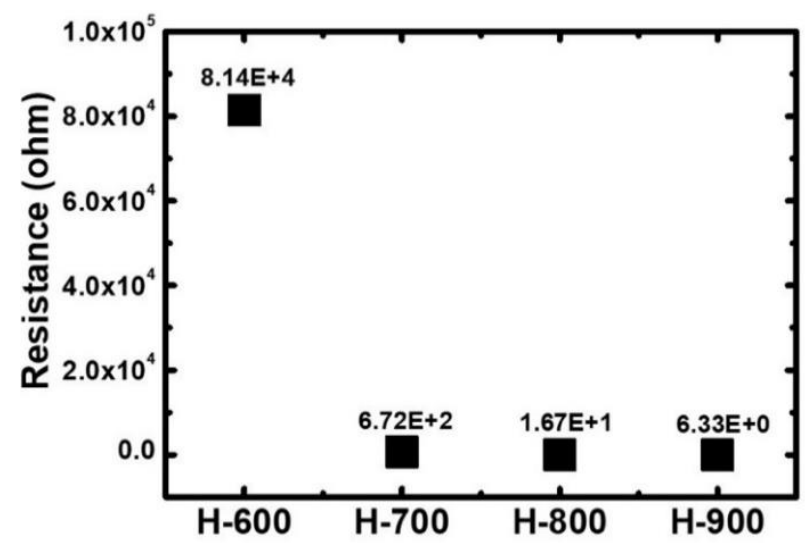

Figure 5. 4-probe resistance values of samples

The initial charge/discharge behavior of half cells made out of carbonized hemp fabric anodes were shown in Fig. 6a. Samples were charged and discharged in the voltage range of $0.001-2 \mathrm{~V}$ at $50 \mathrm{~mA} \mathrm{~g}^{-1}$. The initial charge capacities of all the samples decreased in the following order: H-800 $>\mathrm{H}-700>\mathrm{H}-600>\mathrm{H}-900$ and the initial discharge capacities of all samples decreased in the following order: H-800 $>\mathrm{H}-700>\mathrm{H}-900>\mathrm{H}-600$. Among the all samples, H-800 exhibited the best performance with discharge and charge capacities of 1603 and $538 \mathrm{mAhg}^{-1}$, respectively. The coulombic efficiency of this electrode was $33.56 \%$. The first cycle coulombic efficiencies of H-600, H-700, H-800 and H900 were $33.71,33.72,33.56$, and $47.24 \%$, respectively. The irreversible capacity loss can be connected with the formation of an SEI layer at the surface of the carbonized hemp fabric anodes due to reduction of the electrolyte (around $0.5-0.7 \mathrm{~V}$ ). Another reason for this capacity loss might be irreversible lithium insertion nearby residual $\mathrm{H}$ atoms in the carbon material (Asenbauer et al., 2020).

In Fig. 6b, the charge and discharge capacities of carbonized hemp fabric anodes at different carbonization temperatures were compared for 50 cycles. Accordingly, H-900 showed the most stable cyclic performance. Charge capacity of H-900 changed from 382 to $368 \mathrm{mAh}$ $\mathrm{g}^{-1}$ between $2^{\text {nd }}$ and $50^{\text {th }}$ cycle. Capacity values decreased slightly during first 10 cycles for H-600, H700 and H-800. Charge capacities of H-600, H-700 and $\mathrm{H}-800$ changed from $291,481,531$ to $312,343,438$ mAh $\mathrm{g}^{-1}$ between $2^{\text {nd }}$ and $50^{\text {th }}$ cycle, respectively.
General specific capacity values of $\mathrm{H}-700, \mathrm{H}-800$ and $\mathrm{H}-$ 900 were higher than theoretical capacity of graphite (372 $\mathrm{mAh} \mathrm{g}^{-1}$ ). This might be due to the existence of internal porosity, structural defects and low crystallinity of carbonized hemp fabric. These can create much more space for lithium insertion (Wang et al., 1995). After 10 cycles, capacity values did not change crucially. Among the samples, H-600 showed the worst cyclic performance in terms of capacity. Its low capacity values might be attributed to its high resistance $\left(\sim 8.14 * 10^{4} \Omega\right.$ ) (Striebel et al., 2004).
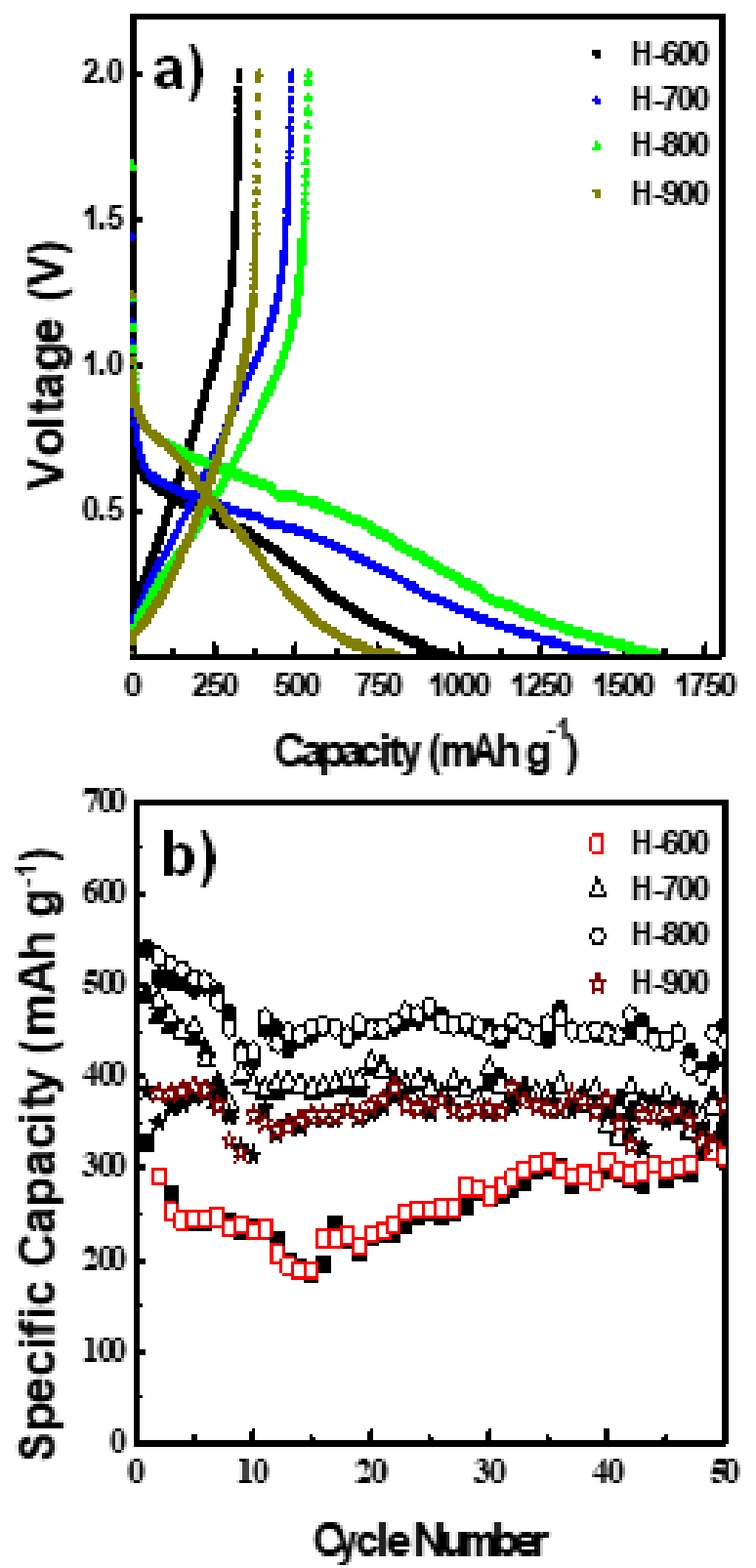

Figure 6. a) The initial charge/discharge curves and b) the cyclic performance of carbonized hemp fabric anodes at different temperatures

\section{Discussion and Conclusions}

In this study, anode performance of hemp-based, binderfree, flexible carbon fabric has been evaluated first time in the literature. The effects of carbonization temperature on physical and electrochemical properties of hempderived carbon fabrics have been studied. Among 
different samples, H-800 gave the best performance in terms of capacity, stability and carbon yield. The better performance might be attributed to high electronic conductivity, aligned Li-ion pathway due to aligned nature of fibers in the fabric, more active sites and amorphous nature of carbon compared with graphite.

The strategy presented in this study could be extended to other cellulose-based fabrics or materials for the next generation green energy storage applications or environmentally friendly flexible electronics.

\section{Acknowledgements}

The authors wish to express their sincere thanks to Ekrem Kabacali for supplying hemp fabric samples and also Emre Cetintasoglu for half-cell preparation.

\section{References}

Asenbauer, J., Eisenmann, T., Kuenzel, M., Kazzazi, A., Chen, Z., Bresser, D. (2020). The success story of graphite as a lithium-ion anode material fundamentals, remaining challenges, and recent developments including silicon (oxide) composites. Sustainable Energy Fuels.

Brosius, D. J. (2006). Natural fiber composites slowly take root. Composites Technology, 12(1), 32-37.

Dumanl1, A. G., Windle, A. H. J. (2012). Carbon fibres from cellulosic precursors: a review. Journal of Materials Science, 47(10), 4236-4250.

Guan, Z., Guan, Z., Li, Z., Liu, J., Yu, K. (2019). Characterization and Preparation of Nano-porous Carbon Derived from Hemp Stems as Anode for Lithium-Ion Batteries. Nanoscale Research Letters, 14(1), 1-9.

Horne, M. R. (2020). Bast fibres: hemp cultivation and production. In Handbook of Natural Fibres (pp. 163196): Elsevier.

Hossain, M. Z., Wu, W., Xu, W. Z., Chowdhury, M. B., Jhawar, A. K., Machin, D., Charpentier, P. A. (2018). High-surface-area mesoporous activated carbon from hemp bast fiber using hydrothermal processing. Journal of Carbon Research, 4(3), 38.

Huang, X. (2009). Fabrication and properties of carbon fibers. Materials, 2(4), 2369-2403.

Ishida, O., Kim, D.-Y., Kuga, S., Nishiyama, Y., Brown, R. M. J. C. (2004). Microfibrillar carbon from native cellulose. Cellulose, 11(3-4), 475-480.

Kwon, J. H., Park, S. B., Ayrilmis, N., Oh, S. W., Kim, N. H. (2013). Effect of carbonization temperature on electrical resistivity and physical properties of wood and wood-based composites. Composites Part B: Engineering, 46, 102-107.

Liu, S., Ge, L., Gao, S., Zhuang, L., Zhu, Z., Wang, H. (2017). Activated carbon derived from bio-waste hemp hurd and retted hemp hurd for $\mathrm{CO} 2$ adsorption. Composites Communication, 5, 27-30.

Mijailović, D. M., Vukčević, M. M., Stević, Z. M., Kalijadis, A. M., Stojanović, D. B., Panić, V. V., Uskoković, P. S. (2017). Supercapacitive performances of activated highly microporous natural carbon macrofibers. Journal of The Electrochemical Society, 164(6), A1061.

Rosas, J. M., Bedia, J., Rodríguez-Mirasol, J., Cordero, T. (2008). Preparation of hemp-derived activated carbon monoliths. Adsorption of water vapor. Ind. Eng. Chem. Res., 47(4), 1288-1296.

Shi, Z., Yue, L., Wang, X., Lei, X., Sun, T., Li, Q. (2019). 3D mesoporous hemp-activated carbon/Ni3S2 in preparation of a binder-free Ni foam for a high performance all-solid-state asymmetric supercapacitor. Journal of Alloys and Compounds, 791, 665-673.

Striebel, K. A., Sierra, A., Shim, J., Wang, C. W., Sastry, A. M. (2004). The effect of compression on natural graphite anode performance and matrix conductivity. Journal of Power Sources, 134(2), 241-251.

Sun, W., Lipka, S. M., Swartz, C., Williams, D., Yang, F. (2016). Hemp-derived activated carbons for supercapacitors. Carbon, 103, 181-192.

Tan, Y., Yang, C., Qian, W., Teng, C. J. (2020). Flowerlike $\mathrm{MnO} 2$ on layered carbon derived from sisal hemp for asymmetric supercapacitor with enhanced energy density. Journal of Alloys and Compounds, $826,154133$.

Um, J. H., Ahn, C.-Y., Kim, J., Jeong, M., Sung, Y.-E., Cho, Y.-H., Yoon, W.-S. (2018). From grass to battery anode: agricultural biomass hemp-derived carbon for lithium storage. RSC advances, 8(56), 32231-32240.

Vukcevic, M., Kalijadis, A., Radisic, M., Pejic, B., Kostic, M., Lausevic, Z., Lausevic, M. (2012). Application of carbonized hemp fibers as a new solid-phase extraction sorbent for analysis of pesticides in water samples. Chemical Engineering Journal, 211, 224-232.

Wang, H., Xu, Z., Kohandehghan, A., Li, Z., Cui, K., Tan, X., Olsen, B. C. (2013). Interconnected carbon nanosheets derived from hemp for ultrafast supercapacitors with high energy. ACS nano, 7(6), 5131-5141.

Wang, S., Matsumura, Y., Maeda, T. (1995). A model of the interactions between disordered carbon and lithium. Synthetic Metals, 71(1), 1759-1760.

Watt, W. (1970). Production and properties of high modulus carbon fibres. Proc. Roy. Soc. Lond. A, 319(1536), 5-15.

Xiong, W., Hu, X., Wu, X., Zeng, Y., Wang, B., He, G., Zhu, Z. (2015). A flexible fiber-shaped supercapacitor utilizing hierarchical NiCo2O4@ polypyrrole core-shell nanowires on hemp-derived carbon. Journal of Materials Chemistry A, 3(33), 17209-17216.

Yang, M., Kim, D. S., Hong, S. B., Sim, J.-W., Kim, J., Kim, S.-S., Choi, B. G. (2017). MnO2 nanowire/biomass-derived carbon from hemp stem for high-performance supercapacitors. Langmuir, 33(21), 5140-5147.

Yang, R., Wang, Y., Li, M., Hong, Y. (2014). A new carbon/ferrous sulfide/iron composite prepared by an in situ carbonization reduction method from hemp (Cannabis sativa L.) stems and its $\mathrm{Cr}$ (VI) removal ability. ACS Sustainable Chem. Eng., 2(5), 12701279. 